\title{
"We don't do that here": Reflections on the Siena experience with dissecting aneurysms of the thoracic aorta in octogenarians
}

\author{
Martin F. McKneally, MD, PhD
}

From the Department of Surgery and Joint
Centre for Bioethics, University of To-
ronto, Toronto General Hospital, Univer-
sity Health Network, Toronto, Ontario,
Canada.
Received for publication Sept 18, 2000;
revisions requested Sept 29, 2000; revisions
received Oct 5, 2000; accepted for publica-
tion Oct 13, 2000.
Address for reprints: Martin F. McKneally,
MD, 77 Forest Grove Dr, Toronto, Ontario,
Canada M2K 1 Z4 (E-mail:
martin.mckneally@utoronto.ca).
J Thorac Cardiovasc Surg 2003;125:S34-5
Originally published in J Thorac Cardio-
vasc Surg 2001;121:202-3.
Copyright $@ 2003$ by The American Asso-
ciation for Thoracic Surgery
0022-5223/2003 $\$ 30.00+0$
doi:10.1067/mtc.2003.218

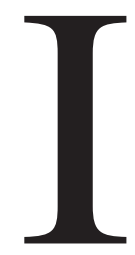
n this issue of the Journal [J Thorac Cardiovasc Surg 2001;121:259-67], Neri and his colleagues provide empirical evidence to support sparing octogenarians, their families, and their caregivers from the tragic experience the authors encountered with operative treatment of type A dissections of the thoracic aorta. Of 24 consecutive surgically treated patients in this age group, 8 died intraoperatively, 12 more died without leaving the hospital, and none of the 4 who were discharged lived beyond 6 months. No survivor returned to "a normal, functioning, integrated" life, the criterion used by the Massachusetts courts to justify a physician's decision to withhold resuscitative measures. ${ }^{1}$ Their report is courageous, because poor outcomes are rarely published; authors and journals usually compete instead to proclaim favorable results of cardiac surgery in older patients. The Siena group recommends a professional guideline that excludes octogenarians from surgical treatment of type A aortic aneurysms. In this commentary, I will argue that creating a local institutional policy, with public as well as professional participation, is a more prudent approach.

When patients, families, and surgeons are required to make decisions about the initiation or withdrawal of heroic life-sustaining treatments, a clear and reasonable institutional policy can be helpful to all. Judicious policies are now widely used to enable the harvest of organs for transplantation and for protection of the irretrievably ill from intubation and resuscitation by cardiac arrest teams.

Guidelines, as suggested by Neri and associates, can be helpful in establishing the standard of care. They are respected by law courts, although not widely adopted by practicing physicians. Guidelines are usually grounded in evidence-based arguments, numerical proofs of futility, and lack of cost effectiveness; these are helpful but insufficient ${ }^{2}$ bases for resolving the ethical quandary we face when an 83-yearold patient arrives in the emergency room with tearing chest pain and a widened mediastinum. When the patient is a "good, and very fit 83 year old," surgeons respond as warriors, rallying to the challenge of our mortal enemy. Desperate family members plead for intervention despite heavy odds. Elderly patients, although more reconciled to human finality than their younger rescuers, often entrust decision making to their doctors and their families. Although some elderly patients want every feasible lifesaving measure, educating them about poor outcomes reduces demand for treatments like cardiopulmonary resuscitation. ${ }^{3}$

Guidelines are generally drawn up by physicians and adopted by physician groups without public participation. British doctors established guidelines that excluded older patients from dialysis; they were vilified when their decision came to public notice. ${ }^{4}$ In contrast, policies (as their Latin root, polites - the citizens, implies) often derive from a broader public process. Public participation is especially appropriate for making decisions to limit the care of citizens who are ill. The United Network for Organ Sharing (UNOS) uses public consultation to ensure the acceptance of its resource allocation decisions. Proposed policies affecting the distribution of organs are sent out "for public comment" to a broad spectrum of citizens, including politicians, patient advocacy groups, and media commentators, to assure transparency and public defensibility of the decision-making process.

Once accepted, publicly reviewed policies are extremely helpful in the proce- 
dural aspects of justice. In principle, age alone, like sex, race, religion, level of intelligence, and other personal characteristics, is not accepted as a morally relevant criterion for just allocation of health care resources. ${ }^{5}$ Benefit and need are the only criteria that should be used to guide these decisions. Appropriately, Neri and his colleagues anchor the logic of their proposal in the lack of benefit from their intervention. Although age alone is not an acceptable criterion for exclusion, it may serve, as argued by Neri's group, as a tightly linked proxy for the ability to benefit from surgical treatment. An institutional policy based on this linkage would stand up to public scrutiny so long as options are offered for exceptional cases to be treated despite the general policy, or to be referred elsewhere. Thoughtful further discussion of the issue of age-based rationing can be found in Beauchamp and Childress's influential textbook of bioethics. ${ }^{6}$

John Paris taught us at the University of Chicago's MacLean Center for Clinical Medical Ethics how effective "We don't do that here" can be as an approach to resolving conflicts when desperate families demand heroic and inappropriate treatments against the advice of caregivers. ${ }^{7}$ The authoritative power of this maxim can be strengthened when it is incorporated into a policy by the specification of "we" to include the community rather than just the physicians, the specification of "that" to a particular treatment or its application in a particular patient group, and the specification of "here" to recognize that the policy is particular to one institution. Policies are restricted to the place and time they are adopted; they may be amended in light of new information or new capabilities. Some become widely adopted, such as the "do not resuscitate" policy of the University of Chicago Hospitals and the policy on discontinuation of life support after brain death as defined at the Massachusetts General Hospital. Such policies are based in part on data from the medical literature and on the experience and values of the institution, rather than "the personal predilections of the practitioner." 8 Hospital policies that govern the allocation of health care resources should be just, equitable, transparent, publicly defensible, implemented by a legiti- mate authority, and subject to appeal in appropriate circumstances. $^{9}$

Rather than attempting to convince professional organizations to adopt treatment guidelines, Neri and his colleagues in the Unita Toracica can help their hospital develop a policy based on their data. The process should include a conversation with informed members of the public, such as former cardiac surgery and intensive care patients, their relatives, and other interested and capable citizens. Public conversation about the acceptance of death, the quality of end-of-life care, and legitimate priority setting will enable them to follow Paris's proscription of heroic treatments that complicate the dying process without preserving purposeful life. I believe that informed octogenarian patients, their families, and their caregivers will welcome a policy on type A thoracic aortic aneurysms that limits the goals of treatment to comfort and dignity.

I am grateful to John Paris and Peter A. Singer for helpful comments on an earlier version of this commentary.

\section{References}

1. In re Dinnerstein. Appeals Court of Massachusetts, Norfolk, 1978. 6 Massachusetts Appellate Court. 466, 380 N.E.2d 134.

2. Martin DK, Singer PA. Priority setting and health technology assessment: beyond evidence based medicine and cost-effectiveness analysis. In: Ham C, Coulter A, editors. The global challenge of health care rationing. Buckingham (UK). Open University Press; 2000. p. 135-45.

3. Murphy DJ, Burrows D, Santilli S, Kemp AW, Tenner S, Kreling B, et al. The influence of the probability of survival on patients' preferences regarding cardiopulmonary resuscitation. N Engl J Med. 1994; 330:545-9.

4. Aaron HJ, Schwartz WB. Rationing hospital care: lessons from Britain. N Engl J Med. 1984;330:52-6.

5. McKneally MF, Dickens BM, Meslin EM, Singer PA. Bioethics for clinicians: 13. Resource allocation. Can Med Assoc J. 1997;157: 163-7. (Available online at www.dma.ca/cmaj/vol-157/issue-2/ 0163.htm).

6. Beauchamp TL, Childress JF. Principles of biomedical ethics. 4th ed. New York: Oxford University Press; 1994. p. 369-72.

7. Paris JJ, Schreiber MD, Statter M, Arensman R, Siegler M. Beyond autonomy: physician refusal of life-prolonging ECMO. $N$ Engl J Med. 1993;329:354-7.

8. Paris JJ, Schreiber MD. Physicians' refusal to provide life-prolonging medical interventions. Clin Perinatol. 1996;23:563-71.

9. Daniels N, Sabin JE. Limits to health care: fair procedures, democratic deliberation and the legitimacy problem for insurers. Philosophy and Public Affairs. 1997;26:303-50. 